\begin{tabular}{|l|l|l|}
\hline \multicolumn{2}{|c|}{ PublisherInfo } \\
\hline \hline PublisherName & $:$ & BioMed Central \\
\hline \hline PublisherLocation & $:$ & London \\
\hline \hline PublisherImprintName & $:$ & BioMed Central \\
\hline \hline
\end{tabular}

\title{
The International BRCA1 /2Carrier Cohort Study: Purpose, Rationale, and Study Design
}

\begin{tabular}{|l|l|l||}
\hline \multicolumn{2}{|c||}{ ArticleInfo } \\
\hline \hline ArticleID & $:$ & 93 \\
\hline \hline ArticleDOI & $:$ & $10.1186 /$ bcr93 \\
\hline \hline ArticleCitationID & $:$ & E010 \\
\hline \hline ArticleSequenceNumber & $:$ & 11 \\
\hline \hline ArticleCategory & $:$ & Non-peer-reviewed research \\
\hline \hline ArticleFirstPage & $:$ & 1 \\
\hline \hline ArticleLastPage & $:$ & 11 \\
\hline \hline & & RegistrationDate : 2000-9-18 \\
\hline ArticleHistory & $:$ & OnlineDate \\
\hline \hline ArticleCopyright & $:$ & The Author(s)2000-9-18 \\
\hline \hline ArticleGrants & $:$ & \\
\hline \hline ArticleContext & $:$ & 130582266 \\
\hline \hline
\end{tabular}



D Goldgar
C Bonnardel
H Renard
O Yaqoubi

\section{The IBCCS Collaborators Group*}

\section{Coordinating Center}

International Agency for Research on Cancer, Lyon, France

D. Goldgar, C. Bonnardel, H. Renard, O. Yaqoubi

\section{Participating Centers}

The following are the coordinating centers and the name of the principal collaborators:

\section{United Kingdom(16 centers)}

CRC Genetic Epidemiology Unit, Cambridge: D. Easton for the EMBRACE collaborators group, S. Peock, N. Haites, T. Bishop.

Netherlands $(9$ centers $)$

The Netherlands Cancer Institute, Amsterdam: R. Brohet, M. Rookus, F. van Leeuwen

France $(28$ centers)

Institut Gustave Roussy, Villejuif: C. Bonaïti-Pellié, C. Noguès for the French Collaborative Network (Groupe Génétique et Cancer), D. Stoppa-Lyonnet

$\operatorname{Austria}(6$ centers)

Universität für Frauenheilkunde, Vienna: T. Wagner

Sweden(2 centers)

Lund University Hospital, Lund: H. Olsson, O. Johannson, A. Borg 
Karolinska Institute, Stockholm: B. Arver, A. Lindblom

$\operatorname{Spain}(3$ centers $)$

Fundacion Jimenez Diaz, Madrid: J. Benitez, A. Osario

Denmark (1 center)

Odense University, Rigshospitalet, Copenhagen: A-M Gerdes

Belgium (1 center)

Institute of Pathology \& Genetics, Gerpinnes (Loverval): C. Sibille

Italy $(1$ center $)$

Istituto Nazionale Tumori, Milan: P. Radice, B. Pisani

Germany (2 centers)

Deutsches Krebsforschungszentrum, Heidelberg: J. Chang-Claude

Heinrich Heine Universität, Frauen Klinik, Düsseldorf: M. Beckmann, B. Kuschel

Iceland ( 1 center)

Icelandic Cancer Society, Reykjavik: J. Eyjford, L. Tryggvadottir, S. Thorlacius

Hungary (1 center)

National Institute of Oncology, Budapest: E. Olah

\section{Introduction}

Breast cancer is the most common cancer affecting women in developed countries. Efforts to decrease breast cancer mortality have focused on early detection and improved treatment. Identification of women at particularly high risk of developing the disease provide a group on whom expensive and rigorous screening programs are cost-effective and a cohort of women who may benefit from trials of chemopreventive agents. The discovery of at least two genes which, when altered, confer markedly increased susceptibility to breast cancer has facilitated the identification of a cohort of individuals at particularly high risk of this disease. Although counseling and genetic testing of at-risk women is now underway in many centers in Europe and North America, the risks of cancer provided to gene carriers is based on limited data obtained from retrospective analyses in families largely selected for high incidence of living affected women. The same limitations apply to our knowledge of the risks of cancer at other sites and the possible interactions of these mutations with other genes and environmental effects (Phelan 
et al. 1996; Rebbeck et al. 1999; Brunet et al. 1998). These studies estimate a risk of breast cancer in female carriers of $\sim 50 \%$ by age 50 and a $\sim 80 \%$ lifetime risk (Easton et al. 1993; Easton et al. 1995; Ford et al. 1998). These two genes also predispose to an approximate $40 \%$ risk of ovarian cancer as well as 3 to 4-fold increased risks of colon $(B R C A 1)$ and pancreatic cancer $(B R C A 2)$ in both male and female carriers and prostate cancer (BRCA1 and BRCA2) in men (Ford et al. 1994; Breast Cancer Linkage Consortium 1999). There have also been published reports that reproductive or other factors may alter the baseline risks conferred by BRCA1 alterations (Goldgar et al. 1995; Narod et al. 1995). Although prophylactic surgery is sometimes used as a means of prevention, there is little or no data regarding the efficacy of these procedures. While several countries have begun national or regional efforts to address these issues prospectively, the sample sizes required for adequate precision of risk estimates and power for detection of risk modification are often beyond the scope of any one center. Accordingly, there is a clear need for international coordination of these efforts with a standardized enrollment and follow-up protocol, and for combined data analyses.

The specific aims of the IBCCS project are to: (1) more precisely estimate the age, sex, and sitespecific cancer risks due to mutations in these genes; (2) determine the importance of known reproductive risk factors in determining these risks; (3) examine the efficacy of prophylactic surgery and other screening/prevention options in high risk women; (4) create an ongoing registry of gene carriers for potential use in future clinical trials.

\section{Eligibility}

Eligible Subjects for the IBCCS cohort are defined as follows:

1. Any identified carrier of a presumed disease predisposing mutation in either the $B R C A 1$ or $B R C A 2$ gene is potentially eligible to be enrolled. This includes both men and women, those who currently have cancer (at any site), as well as those who are currently asymptomatic.

2. Carriers must be informed of their mutation status.

3. Subjects must be over 18 , mentally capable, and have given informed consent to participate in a longitudinal study.

The decision to include only carriers of a proven $B R C A 1$ or $B R C A 2$ mutation in the cohort stems from the desire to maximize the amount of information collected and lessen the follow-up burden, relative to the cost of administering the study. However, some of the participating studies at the national level (e g, UK study) are including similar data on individuals who are found not to be carriers, while others are including subjects who have a risk defined only by family history. The rationale for requiring point 2 is to best reflect the future (or current) clinical setting in which subjects will be informed of their test result and given counseling through the normal clinical practice. In this fashion the risk estimates derived from the study will be most applicable to individuals undergoing such testing in the future. Moreover, these women will be making more informed choices regarding lifestyle, prevention, and screening choices. 


\section{Procedure}

Eligible subjects may enter the cohort by one of two distinct mechanisms: through oncogenetics/ family cancer clinics, or by previous participation in research family studies. In general, subjects identified through family cancer clinics will have been identified within a year of October 1 1998. The administration of the questionnaire can take place either before or after the subject receives the notification of their carrier status, depending on the organization of the individual cancer/genetics center. If the questionnaire is administered before the results of the genetic test are provided to the subject, (e g, at the first pre-test counseling session) it will be necessary that the same procedure is followed for all subjects, even if the investigator is aware of the gene-carrier status of the subject. This is necessary to avoid situations where, for example, two sisters are awaiting testing and the fact that only one is given a questionnaire or invited to participate in the IBCCS study, will allow the inference of the mutation status prior to delivery of the information in the proper setting. Although this means that subjects who are not eligible for the cohort study because they are non-carriers will unnecessarily (at least for the IBCCS) be given the questionnaire, this data could be used to compare baseline data between carriers and non-carriers in those centers which follow this procedure. For subjects entered into this fashion, the date of entry into the cohort (i e, the date in which the follow-up starts) will be the date that the subject is notified that they are a carrier of a deleterious mutation in $B R C A 1 / 2$. In other clinical settings it may be more convenient to administer the questionnaire after the subject has been notified of their mutation-carrier status. In this case, the procedure will be to: 1) invite eligible (i e carriers) subjects to participate in the IBCCS study; 2) obtain the appropriate informed consent from the subject to permit follow-up; and 3) administer the questionnaire. In this case the date of enrollment into the IBCCS cohort is the date that the questionnaire is completed.

In the case of research subjects, those who have been identified as part of previous studies but who have since been notified of their carrier status in the past are eligible for the IBCCS cohort. In those cases where these subjects were previously given a questionnaire similar to the IBCCS questionnaire (to be examined on a case-by-case basis for compatibility with the IBCCS data), information from the previous questionnaire will be treated as the original questionnaire, follow-up will start at the time of notification of test result, and the subject will be administered the IBCCS questionnaire as their first follow-up questionnaire. It is required that complete cancer incidence, medical history, and mortality data is obtained on all such subjects (i e, not just the subjects who are alive in 1998). Similarly, subjects who were notified of their test result in the past, but were not given substantially similar questionnaires will be given the IBCCS questionnaire as their baseline questionnaire, with follow-up to start at the time of questionnaire completion.

\section{Questionnaire}

Where possible, investigators were encouraged to utilize the IBCCS questionnaire (suitably translated into the nine other languages used in participating centers). The use of a standardized questionnaire will facilitate the entry of all relevant data into the database and allow for a more homogeneous (and therefore more powerful) combined analysis. The use of other questionnaires (for example, those used in 
ongoing epidemiological studies of high-risk families) was permitted, but other such questionnaires were required to contain the vast majority of the information contained in the IBCCS questionnaire. As much as possible, the common items on other questionnaires were defined and formatted as closely as possible to that of the IBCCS questionnaire. Although ideally the questionnaire would be done through in-person or telephone interview by a trained interviewer, the subjects will be allowed to self-administer the questionnaire and return it by post to the local center. In this case, the local center coordinator should check each questionnaire for completeness before sending it on to the Coordinating center in Lyon. A separate, shorter, questionnaire is used for male carriers. In addition to the data collected on the questionnaire, all centers provide a standard pedigree drawing of each family participating in the study. As detailed in the questionnaire, the risk factor data focuses on relatively detailed reproductive factors and hormone usage, with only moderately detailed information on alcohol and tobacco consumption. In order to keep the questionnaire as short and simple as possible, it was decided to avoid the collection of dietary information, as part of the core data, although individual centers may be collecting this data in their own separate studies. In addition to the general questions related to disease asked on the questionnaire, more detailed pathology information will be collected (normally taken from the path reports) for each existing and new occurrence of breast or ovarian cancer in study participants. Furthermore, for each incident case of cancer occurring during the study follow-up interval, a detailed clinical questionnaire containing specific treatment information will be filled in by the investigator.

\section{IBCCS Database}

Data from the IBCCS study will be centralized in a large ORACLE (Oracle inc.) database designed and maintained at the coordinating center in Lyon. The overall principal questionnaire database is composed of 244 fields arranged in 45 distinct data tables, each indexed and linked in a relational scheme. Each field contains data quality checks at the point of data entry. No nominative data will be transferred to the coordinating center. Each subject will be identified by key identifying fields including center/family/individual ID numbers and date of birth. At regular intervals, (e g, 20 enrolled subjects) the completed questionnaires except the page containing nominative data to be retained by the local center, will be sent to the IBCCS coordinating center in Lyon for entry into the IBCCS database. An electronic version of the data contributed from each local center will be returned to the local center in a desired format (e g, text, EXCEL, etc.) In general this will apply to the centers using the IBCCS questionnaire. Alternatively, for larger centers conducting National/Regional studies, and/or who will be using their own questionnaire, the procedure will be to enter the data into a local database. At regular intervals (e g, quarterly), the data will be transferred electronically via ftp and be translated into the common IBCCS data format using a set of center-specific software procedures written for this purpose at the coordinating center in Lyon. In both cases, a series of consistency checks will be implemented to identify possible coding errors. Any inconsistencies detected will be communicated as quickly as possible to the local data coordinator for clarification.

\section{Biological Samples}


Although the collection and storage of a central repository of biological specimens (Blood, Serum, DNA, Tumor) is not formally a part of the IBCCS study, it is our goal that these will be collected whenever possible, and the data concerning the type of sample, date of collection, and place of storage will be noted on the IBCCS questionnaire to be stored in the database. This will allow the better organization of specific collaborative projects requiring biological samples from mutation carriers.

\section{Follow-up}

Each subject entered into the cohort will be given a follow-up questionnaire at regular intervals following enrollment. Specifically, the follow-up assessment will be performed one year after the entry into the study, and subsequently every two years. The follow-up questionnaire will be a subset of the original questionnaire on all items that are subject to change, with particular focus on menopausal status, hormone usage through either HRT or OC use, and in screening and prevention practices, including any new prophylactic surgeries. In addition, we will ask specifically about any changes in lifestyle, screening practices, and diet, since the last questionnaire. At a minimum, this will continue until 5 years of follow-up ( 3 follow-up questionnaires) have been completed. After this time, we encourage the continuation of the active follow-up for as long as possible, but recognize that this could place an undue burden on the investigators. If active follow-up is not to be done, tracking of cohort participants to identify incident cancers will be done through the appropriate cancer registry (in centers where this is feasible) by linking individual identifier information retained at each center to the registry.

\section{Expected Total Enrollment and Number of Cases}

Based upon the initial experiences of the family cancer clinics at each participating center, we anticipate that a total enrollment of 2000 women and 200 male subjects into the cohort is feasible by March 12001 . We expect that at least $50 \%$ of these subjects will be enrolled through the large national studies in the UK, Netherlands, and France.

The expected number of cases of breast and ovarian cancer occurring during the follow-up period will be a function of a number of factors including the number of subjects enrolled, length of follow-up, age distribution of the cohort, the age-specific risks of cancer assumed, the ratio of affected to unaffected carriers, the proportion of unaffected women electing to have preventive surgery, and the relative proportions of $B R C A 1$ and $B R C A 2$ mutations. In the table below we have tried to make some calculations about the number of cancers we might observe under some reasonable assumptions about these factors as described in more detail below.

We further assume that $2 / 3$ of the women will carry a $B R C A 1$ mutation, vs. $1 / 3 B R C A 2$, and that among $B R C A 1$ carriers affected at the time of enrollment into the cohort, $2 / 3$ will have breast, $1 / 3$ ovarian cancer; for $B R C A 2$ carriers $80 \%$ will present with breast cancer. For the calculations below, we 
have used the risk estimates for BRCA1 and BRCA2 as produced by the BCLC (Ford et al. 1994; 1998). Among women affected with breast cancer, we assume $80 \%$ will have prophylactic contralateral mastectomy and that all women with ovarian cancer will have total oophorectomy. Under these assumptions, the table below shows the expected number of breast and ovarian cancer cases as a function of the ratio of affected to unaffected gene carriers enrolled, the rates of prophylactic surgery in unaffected women, and the length of follow-up, assuming that 2000 female gene carriers are entered into the study.

As can be seen from the above table, adequate $(>0.8)$ power is obtained for ovarian cancer only with long term follow-up and a common exposure associated with a relatively large effect. For breast cancer, however, a doubling of risk can be detected with 5 years of follow-up, provided that it is a reasonably common exposure (e g, OC use).

\section{Summary}

In organizing this international effort, our goal was to provide a standardized set of procedures and questionnaire data for a group of centers doing $B R C A 1 / 2$ testing, either in a research or clinical context. The IBCCS study includes data both from large parallel studies being conducted in the UK, Netherlands, and France, and from small individual centers in which the IBCCS is providing the impetus and some resources to collect the necessary data. These data can be used to address prospectively some basic questions concerning the natural history of $B R C A 1$ and $B R C A 2$ carriers. Many of these questions, notably those concerning outcome and response to treatment are difficult, if not impossible, to address in a retrospective fashion. Other analyses, such as mutation specific risks, or some of the rarer environmental/lifestyle exposures, other cancer sites etc. are likely to require a sample size larger than even any of the national studies can obtain on their own. As new chemopreventive or targeted therapeutic agents become available, the IBCCS can provide a potential resource of high-risk women who may wish to participate in clinical trials of these agents. The knowledge gained from this prospective observational study will allow the family cancer clinics in each country to provide more accurate risk information to women who are found to be gene carriers in these programs thus allowing them to make informed choices regarding their options for prevention and screening. This study will interact with other European Community-funded studies such as the European Network of Cancer Registries (for verifying and tracking cancer incidence in those centers covered by complete registries), the European Breast Cancer Linkage Consortium, which coordinates collaborative research in breast cancer genetics, and the EPIC prospective study of nutrition and cancer which will allow (where the populations overlap) the comparison of our results with age-specific cancer rates in a normal-risk population. Moreover, we have coordinated the questionnaires and timing of the study to allow pooling of our data with parallel studies in Canada (with S. Narod), USA (B. Weber), and Australia (J. Hopper and the KconFab project). Although enrollment has only just begun, we believe that in the future, the IBCCS study has the potential to be an important aid in our understanding of the role of the $B R C A 1$ and $B R C A 2$ genes in breast and ovarian cancer. 


\section{Show Char Content Hide Char Content}

Table 1 Assumed Age Distribution (based on first 125 female subjects enrolled):

\begin{tabular}{|l|l|c|c|c|c|}
\hline Age: & $20-29$ & $30-39$ & $40-49$ & $50-59$ & $60+$ \\
\hline Proportion & 0.04 & 0.32 & 0.26 & 0.28 & 0.10 \\
\hline
\end{tabular}

\section{Show Char Content Hide Char Content}

Table 2. Expected cases of breast and ovarian cancer in the IBCCS cohort as a function of the proportion of unaffected subjects, prophylactic surgery rates and length of follow-up. A cohort of 2000 women is assumed.

\begin{tabular}{|l|l|l|l|l|l|l|}
\hline Aff:Unaff & $\%$ Mastectomy & $\%$ Oophorectomy & Expected Breast Cancers & Expected Ovarian Cancers \\
\hline & & & 5 yrs & 10 yrs & 5 yrs & 10 yrs \\
\hline $2: 1$ & 10 & 30 & 55 & 104 & 14 & 29 \\
\hline $1: 1$ & 10 & 30 & 75 & 143 & 17 & 35 \\
\hline $1: 2$ & 10 & 30 & 96 & 181 & 20 & 41 \\
\hline $2: 1$ & 30 & 50 & 44 & 82 & 10 & 20 \\
\hline $1: 1$ & 30 & 50 & 60 & 112 & 12 & 24 \\
\hline $1: 2$ & 30 & 50 & 76 & 142 & 14 & 28 \\
\hline $2: 1$ & 50 & 70 & 32 & 61 & 6 & 12 \\
\hline $1: 1$ & 50 & 70 & 43 & 82 & 7 & 15 \\
\hline $1: 2$ & 50 & 70 & 54 & 103 & 9 & 17 \\
\hline \hline
\end{tabular}

\section{Show Char Content Hide Char Content}

Table 3. Power to detect differences in risk due to environmental effects in the prospective study as a function of follow-up time, exposure frequency and risk ratio of the exposure. The total number of cancer cases is assumed to be those given in table 1 above assuming 2000 females enrolled, 2/3 of which are unaffected at time of enrollment, a $30 \%$ rate of prophylactic mastectomy and a $50 \%$ rate of oophorectomy.

\begin{tabular}{|l|l|l|l|l|l|}
\hline & & \multicolumn{2}{|c|}{ Breast Cancer } & \multicolumn{2}{c|}{ Ovarian Cancer } \\
\hline Risk Ratio & Exposure Frequency & 5 yrs & 10 yrs & 5 yrs & 10 yrs \\
\hline 2 & 0.1 & 0.64 & 0.87 & Not done & Not done \\
\hline & 0.3 & 0.80 & 0.98 & Not done & Not done \\
\hline 3 & 0.1 & 0.95 & 1.00 & 0.48 & 0.68 \\
\hline 5 & 0.3 & 0.98 & 1.00 & 0.56 & 0.82 \\
\hline & 0.1 & 1.00 & 1.00 & 0.76 & 0.93 \\
\hline
\end{tabular}




\begin{tabular}{|l|l|l|l|l|l|}
\hline & 0.3 & 1.00 & 1.00 & 0.81 & 0.97 \\
\hline
\end{tabular}

\begin{tabular}{||l|l|l||}
\hline \multicolumn{2}{|c|}{ BodyRef } \\
\hline \hline FileRef & $:$ & BodyRef/PDF/13058_2000_Article_93.pdf \\
\hline \hline TargetType & $:$ & OnlinePDF \\
\hline
\end{tabular}

\section{Acknowledgements}

The IBCCS is funded in part by a grant from the European Union (DG-V 97/CAN/33848). The Embrace study is funded by the Cancer Research Campaign, The Netherlands study is funded by a grant form the Dutch Cancer Research Society, and the French study is supported by a grant from the Ligue Nationale Contre le Cancer.

\section{References}

1. Breast Cancer Linkage Consortium : Cancer risks in BRCA2 Mutation Carriers. J Nat Cancer Inst. 1999, 91 (15): 1310-1316.

2. Brunet JB, Ghadirian P, Rebbeck TR, Lerman C, Garber JE, Tonin PN, Abrahamson J, Foulkes WD, Daly M, Wagner-Costalas J, Godwin A, Olopade OI, Moslehi R, Liede A, Futreal PA, Weber BL, Lenoir GM, Lynch HT, Narod SA: Effect of smoking on breast cancer in carriers of mutant BRCA1 or $B R C A 2$ genes (Report). J Nat Cancer Inst. 1998, 90 (10): 761-766. 10.1093/jnci/90.10.761.

3. Easton DF, Bishop DT, Ford D, Crockford GP: Genetic linkage analysis in familial breast and ovarian cancer: results from 214 families. Am. J. Hum. Genet. 1993, 52: 678-701.

4. Easton DF, Ford D, Bishop DT: Breast and ovarian cancer incidence in BRCAl-mutation carriers. Am J Hum Genet. 1995, 56: 265-271.

5. Ford D, Easton DF, Bishop DT, Narod SA, Goldgar DE: Risks of cancer in BRCA1-mutation carriers. Breast Cancer Linkage Consortium. Lancet,. 1994, 34: 692-695. 10.1016/ S0140-6736(94)91578-4.

6. Ford D, Easton DF, Stratton M, Narod S, Goldgar D, Devilee P, Bishop DT, Weber B, Lenoir G, Chang-Claude J, Sobol H, Teare MD, Struewing J, Arason A, Scherneck S, Peto J, Rebbeck TR, Tonin P, Neuhausen S, Barkardottir R, Eyfjord J, Lynch H, Ponder BAJ, Gayther SA, Birch JM, Lindblom A, Stoppa-Lyonnet D, Bignon Y, Borg A, Hamann U, Haites N, Scott RJ, Maugard CM, Vasen H, Seitz S, Cannon-Albright LA, Schofield A, Hedman MZ: Breast Cancer Linkage Consortium: Genetic heterogeneity and penetrance analysis of the $B R C A 1$ and $B R C A 2$ genes in breast cancer families. Am J Human Genetics,. 1998, 62: 676-689. 10.1086/301749. 
7. Goldgar DE, Rowe K, Lewis CM, McDonald M, Gholami K, Cannon-Albright L, Skolnick M: Genetic epidemiology of familial ovarian cancer in Utah. In: Ovarian Cancer - 3, edited by Sharp F, Mason P, Blackett T, and Berek J Chapman \& Hall Medical. 1995, 13-21.

8. Narod SA, Goldgar D, Cannon-Albright L, Weber B, Moslehi R, Ives E, Lenoir G, Lynch H: Risk modifiers in carriers of BRCA1 mutations. Int J Cancer,. 1995, 64: 394-398.

9. Phelan CM, Rebbeck TR, Weber BL, Devilee P, Ruttledge MH, Lynch HT, Lenoir GM, Stratton MR, Easton DF, Ponder BAJ, Cannon-Albright L., Larsson C, Goldgar DE, Narod SA: Ovarian cancer risk in $B R C A 1$ carriers is modified by the HRAS1 variable number of tandem repeat (VNTR) locus. Nature Genetics,. 1996, 12: 309-311.

10. Rebbeck TR, Kantoff PW, Krithivas K, Neuhausen S, Blackwood MA, Godwin AK, Daly MB, Narod SA, Garber JE, Lynch HT, Weber BL, Brown M: Modification of BRCAl-associated breast cancer risk by the polymorphic androgen-receptor CAG repeat. Am J Hum Genet,. 1999, 64 (5): 1371-1377. 10.1086/302366. 